\title{
Is it Pemphigus Vulgaris or Toxic Epidermal Necrolysis? A dilemmatic condition to confirm diagnosis
}

\author{
E. Fitriana Sari*, Titiek Setyowati** \\ *Resident Department of Oral Medicine Faculty of Dentistry Universitas Indonesia \\ **Department of Oral Medicine Faculty of Dentistry Universitas Indonesia
}

\begin{abstract}
Pemphigus Vulgaris and Toxic Epidermal Necrolysis both are life threatening diseases. Phemphigus Vulgaris is a mucocutaneous autoimmune disease while Toxic Epidermal Necrolysis is cutaneus drug hypersensitive reaction. It suppose to be easy to distinguish one another, but confusion happen when the clnical appearance is atypical. We report a case which become dilemmatic because of some clinical and histological features can be a manifestation from pemphigus vulgaris or toxic epidermal necrolysis. Patient was under supervision by both Oral Medicine Department and Dermatology and Venereal Department. The ulcerative, erosive and sloughing lesion in oral mucousa has been treated successfully by administrating Prednisone $60 \mathrm{mg} /$ day for almost two months. Epidermal sloughing of more than 10\% of total body surface area due to epidermolisis was treated with Methylprednisolone within two months and the epidermolisis is resolved.
\end{abstract}

Key words: Pemphigus Vulgaris, Toxic Epidermal Necrolysis

\section{INTRODUCTION}

Pemphigus Vulgaris (PV) and Toxic Epidermal Necrolysis (TEN) are diseases that threaten life. $\mathrm{PV}$ is a very severe vesicle autoimmune condition that may trigger vesicle, vesicle and ulceration in mucocutan..$^{1,2}$ TEN is an acute hypersensitivity condition that is mostly triggered by drugs. ${ }^{1,3}$ TEN has a mortality rate of $20-40 \% .^{1}$

We report a case study which started with oral mucous lesions. The lesions were ulcerative lesions with expanded erosive area accompanied by sloughing in buccal and labial mucous and lateral part of the tongue which applies for pemphigus vulgaris clinical appearance. The lesions were treated using $60 \mathrm{mg}$ prednison per day with good cure result. Two months later, the patient came back with similar lesions in oral mucous with additional of target lesions on foot, back, and neck skin with unbroken vesicle in the back, crust on the upper and lower lips and under the left eye. Diagnosis became erythema multiforme with differential diagnosis Steven Johnson's Syndrome, and Toxic Epidermal Necrolysis. The histological features of biopsy results of the back skin support pemphigus vulgaris feature but the histological feature of the lower labial show allergic condition (hypersensitivity) that supports Toxic Epidermal Necrolysis condition. This will become a dilemma in determining precise diagnosis of this case.

\section{CASE REPORT}

A 75 year old female patient from Batak 
tribe visited oral disease clinic of RSUPN-CM on 31 January 2008. The patient is referred from M.K. hospital with a working diagnosis of aphthous stomatitis and candidiasis, multiple abscess e.c. dental radix gangrene.

The patient complained of stomatitis and oral fungus as well as spitting blood and pus since December 2007. Because of the condition, the patient had been treated in several hospitals in Medan but the condition was not resolved so that she was referred to Cipto Mangunkusumo Central Hospital/RSUPN-CM. Patient does not have a history of recurrent stomatitis, have a history of cold and dust allergy, have had depression and is treated by a psychiatrist since 20 years ago using antidepressant and anticonvulsant since 1978 until now. The most frequently used medicine is benzodiazepine (valium). At that moment the patient was having a quite difficult problem with his family.

In the first visit, the general condition of the patient was weak because it was difficult for him to eat and drink. There was no skin lesion.

In extraoral examination we found swollen lymph node which is still in normal limit, asymmetric face with left part wrinkled, the left lip corner dropped. In palpation, there was a thickening angularis area of the left cheek, left mandible. The left eye lid looked shrinking and crumpled, but there was no lesion on the eye.

During intraoral examination, we found poor oral hygiene with a broad eroded area all over the mucous with irregular borders. There was also sloughing in the right and left buccal mucous, upper and lower labial, lateral tongue and papilla total depapillation. From this clinical appearance, we diagnosed him as a suspect for Pemphigus vulgaris dd/Membrane Mucous Phempigoid, Erythema Multiforme.

A biopsy was performed to the lower labial mucous with a histophatological results showing a chronic inflammation with many local eosinophils and inflammatory cell infiltration. The direct immunofluorescent examination result did not show the presence of immunoglobulin, complement or fibrinogen. From the results of the supporting examination we concluded that the temporary patient diagnosis did not support pemphigus vulgaris but there is a big possibility of allergic condition leading to temporary diagnosis of stomatitis related to allergy and stress. However, the possibility of pemphigus vulgaris could not be neglected yet due to the limited specific examination available.

We gave Prednisone $60 \mathrm{mg} /$ day and instruction to maintain the cleanliness of the mouth, improving oral hygiene, giving multivitamin and a suggestion for soft diet that is high in calories and protein. The therapy was performed for 2 months and there was a quite good response in terms of $90 \%$ of the oral lesions were resolved. The patient wanted to go home to Medan and refused further treatment because she felt that she was better although there were still some lesion in right buccal mucous and lateral tongue. The lesions in other mucous have resolved.

Two months later, the patient came back to RSUPN-CM after visiting several hospitals with a worse condition. There were target lesion on foot, back and neck skin. Unbroken on the back, crust on the upper and lower lips and under the left eyes were found. On oral mucous, there was comprehensive sloughing and eroded area. The patient experienced hypersalivation, difficulty to swallow and to talk. According to the patient's family there was a chancroid like wound in the genital area. The condition had been recurrent since 2 weeks before. The patient was referred to the dermatology and venereal disease department for in-patient treatment and join-therapy was continued.

By the Dermatology and Venereal Disease Department, the first diagnosis was Erythema multiforme with differential diagnosis Steven Johnson Syndrome (SJS) and Toxic Epidermal Neucrolysis (TEN). The reply for the referral to the opthalmologist stated that there was dry eye e.c. SJS. Further diagnosis tended to be TEN with SCORTEN 2. However, the diagnosis of pemphigus vulgaris could not be eliminated because the biopsy was not performed yet. On the second day, a debridement of oral cavity was done and lip topical cream with hirocortisone was given for the lip crust.

A biopsy was performed to the patient by removing a newly developed vesicle on the back epidermis one week after the first day of in patient with a histopatological feature of parsial subepidermal vesicle in suprabasal with acantholytic cells inside. The underlying dermis 


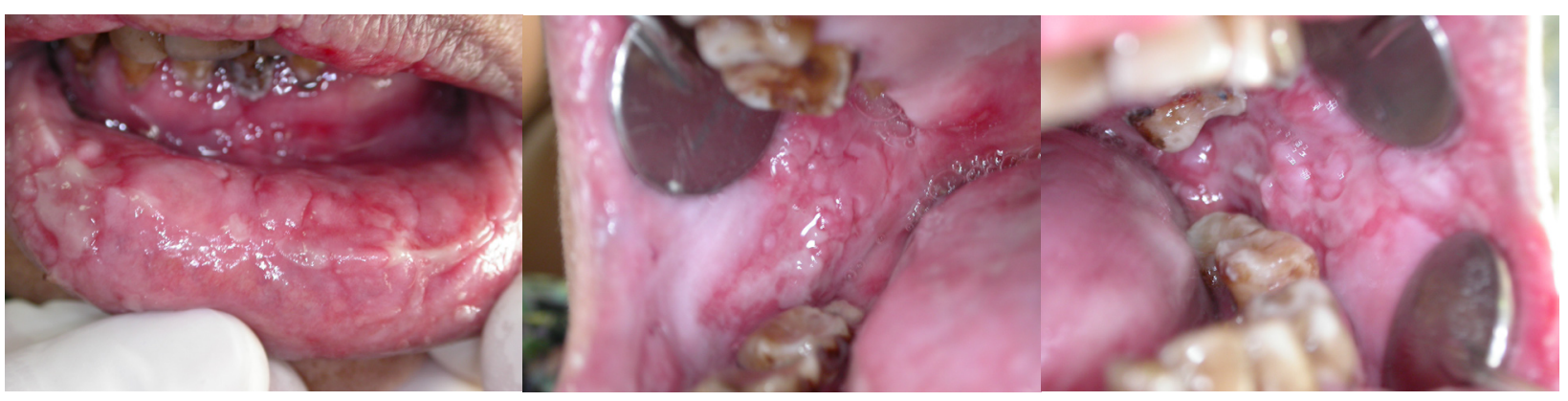

Figure 1. First appointment in Oral Medicine Department.

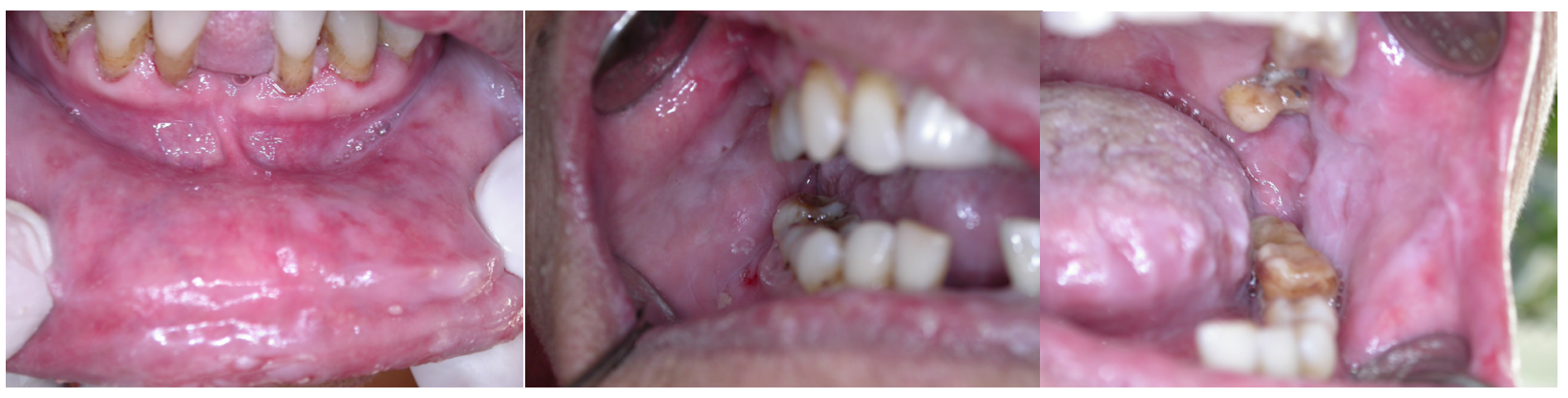

Figure 2. Control after Prednison comsumption $60 \mathrm{mg} /$ day for two month.

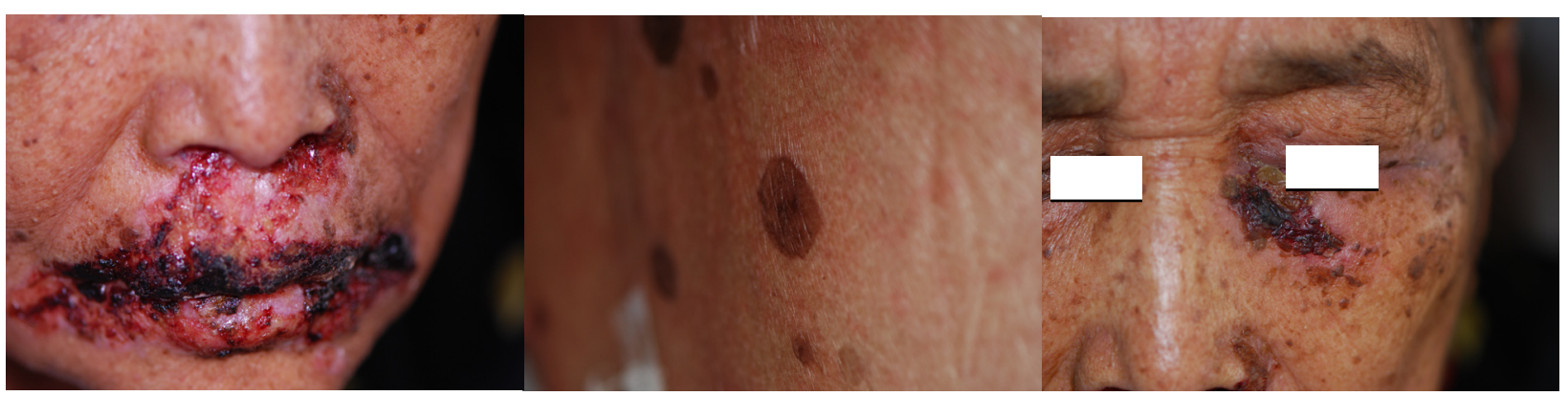

Figure 3. Two months later.

was filled by lymphocyte inflammatory epithelial and eosinophil. The histological feature supports the diagnosis of pemphigus vulgaris but the direct immunofluorescent examination failed to present immunoglobulin sediment, complement and fibrinogen. The result of the direct biopsi immunofluorescent examination from the skin and from the lower labial mucous showed similar feature. Since then the dermatology and venereal disease department confirmed that the fixed diagnosis for this patient was pemphigus vulgaris.

Patient then received intravenous methylprednisolon $3 \times 31.25$ gram, ceftriaxon $1 \times 2$ gram, omeprazole $1 \times 4 \mathrm{U}$ and was instructed to be provided by balance liquid intake, with liquid diet $6 \times 250 \mathrm{cc}$. In the next visit, the patient complained of pain in oral cavity especially on the tongue and the corner of the mouth. The lip crust was already lessened. The intraoral appearance in tongue dorsum showed white hairy tongue that was very thick but cleanable, leaving reddish area behind with occasional bleeding in the underlying tissue. There was a pseudomembrane in right and left buccal mucous. On the corner of the lips there was easily bled fissure. We concluded that there was oral candidiasis and angular cheilitis due to high methyl prednisolone dose, soft diet consumption and difficulty to clean the mouth because the patient complained of very painful oral lesion plus the immunocompromized condition of the patient. Therefore, Mycostatin oral suspension $4 \times 2 \mathrm{cc}$ per day and daktarin cream were given for angular cheilits. The improvement of oral candidiasis and reduced pain complaint on the mouth, tongue 
and mouth corner was seen after mycostatin oral suspension was given for 5 days. The ulcerative and erosive lesion as well as sloughing in buccal and labial mucous and tongue was also improved.

The result of IgE examination of 665 $\mathrm{kU} / \mathrm{L}$, which is 6 times higher than normal was found showing that the patient experienced hypersensitivity. Meanwhile, the examination for HSV1 antibody IgG, HSV 2 lgG, and M showed negative results. The test for HSV 1 \& 2 antibody was performed to see the relationship with erythema multiforme.

The patient was treated at the dermatology and venereal disease department for almost 2 months with apathetic psychological condition and the patient refused to have his mouth cleaned. Patient was given diet through NGT. The last intraoral condition showed ulcerative lesion, sloughing and errosive area but the size of the lesion could not be determined because it was difficult to ask the patient to open his mouth. Coating in tongue dorsum was also very thick. It was emphasized to the patient and the family to maintain good oral hygiene and to take the medicine as instructed. $90 \%$ of the oral lesion was better while the general condition still needed further recovery.

\section{DISCUSSION}

In this case, there are several things that create dilemma in making accurate diagnosis as stated in the table below. From the table below we can observe that the intraoral clinical appearance, age and gender predilection and histological feature from the back skin biopsi supports Phempigus Vulgaris (PV) diagnosis although the most frequent intraoral lesion predilection area, i.e. the palate and gingiva, does not show unique lesions in this patient. ${ }^{1,2}$

The histological feature of the biopsy result of the back skin showed partial subepidermal vesicle in suprabasal and inside, acantholitic cells were found. This indeed supports the diagnosis of pemphigus vulgaris. However, the result of the direct immunofluorescent from back biopsy and lower lip biopsy did not show the presence of Immunoglobulin G (IgG) and complement that

Table 1. Several criteria of patients showing Pemphigus Vulgaris and Toxic Epidermal Necrolysis that creates dilemma. ${ }^{1-7}$

\begin{tabular}{|c|c|c|}
\hline Patient Condition & Phempigus Vulgaris (PV) & Toxic Epidermal Necrolysis (TEN) \\
\hline Female & Predilection in female & No gender predilection \\
\hline Age 75 years old & Age predilection: middle age or more & No age predilection \\
\hline $\begin{array}{l}\text { Intraoral clinical appearance: ulcerative } \\
\text { and eroded lesion, sloughing }\end{array}$ & $\begin{array}{l}\text { Intraoral clinical appearance: } \\
\text { Vesicular lesion, blister, ulcerative, } \\
\text { erosive, sloughing }\end{array}$ & $\begin{array}{l}\text { Intraoral clinical feature: ulcerative and } \\
\text { eroded lesion, sloughing but not always }\end{array}$ \\
\hline $\begin{array}{l}\text { Epidermal sloughing > 10\% total body } \\
\text { surface area (TBSA) }\end{array}$ & $\begin{array}{l}\text { Epidermal sloughing with no extended } \\
\text { border. Bevry rupture vesicle and }\end{array}$ & $\begin{array}{l}\text { Epidermal sloughing > }>10 \% \text { total body } \\
\text { surface area (TBSA) }\end{array}$ \\
\hline $\begin{array}{l}\text { Biopsy histological feature from the } \\
\text { back skin: there were partial suprabasal } \\
\text { vesicle and acantholitic cells as well as } \\
\text { eosinophils } \\
\text { Biopsy histological features of } \\
\text { lower labial: there are a lot of local } \\
\text { eosinophils and inflammatory cells } \\
\text { infiltration }\end{array}$ & $\begin{array}{l}\text { Histological feature: extensive } \\
\text { progressive acantholisis that leads to } \\
\text { suprabasal vesicle }\end{array}$ & $\begin{array}{l}\text { Histological feature: keratinocyte } \\
\text { apoptosis in epidermis with dermo- } \\
\text { epidermal separation that will produce } \\
\text { vesicle. Sometimes the result is not } \\
\text { specific. }\end{array}$ \\
\hline $\begin{array}{l}\text { Direct immunofluorescent from } \\
\text { back skin biopsy \& lower labial: no } \\
\text { immunoglobulin, complement and } \\
\text { fibrinogen }\end{array}$ & $\begin{array}{l}\text { Direct immunofluorescent shows the } \\
\text { presence of immunoglobulin G (lg G) } \\
\text { and keratinocyte-bound complement }\end{array}$ & $\begin{array}{l}\text { Histological examination and serum } \\
\text { Fas and FasL examination are usually } \\
\text { enough. }\end{array}$ \\
\hline $\begin{array}{l}\text { ANA examination was not done } \\
\text { IgE }=665 \mathrm{kU} / \mathrm{L} \square 6 \text { times normal values, } \\
\text { showing hypersensitivity }\end{array}$ & Autoimmune disease & It is a hypersensitivity reaction. \\
\hline $\begin{array}{l}\text { Consumption of antidepressant and } \\
\text { anticonvulsant since } 20 \text { years ago. } \\
\text { Especially benzodiazepine. }\end{array}$ & $\begin{array}{l}\text { Drugs suspected as triggering this } \\
\text { disease: penicillin, captopril. }\end{array}$ & $\begin{array}{l}\text { Drugs suspected as triggering this } \\
\text { disease:Sulfonamid, quinolone, } \\
\text { phenobarbital, phenytoin, } \\
\text { carmabazepine, benzodiazepine }\end{array}$ \\
\hline $\begin{array}{l}\text { There were target lesions, vesicle, crust } \\
\text { on the lips, genital lesion, dry eyes }\end{array}$ & $\begin{array}{l}\text { Skin lesion, usually only epidermal } \\
\text { sloughing. Rarely showing crust. }\end{array}$ & $\begin{array}{l}\text { It may be a development of more } \\
\text { severe disease from SJS and EM. Can } \\
\text { give appearance of target lesion, crust } \\
\text { on the lips, eye lesion and genital lesion }\end{array}$ \\
\hline
\end{tabular}




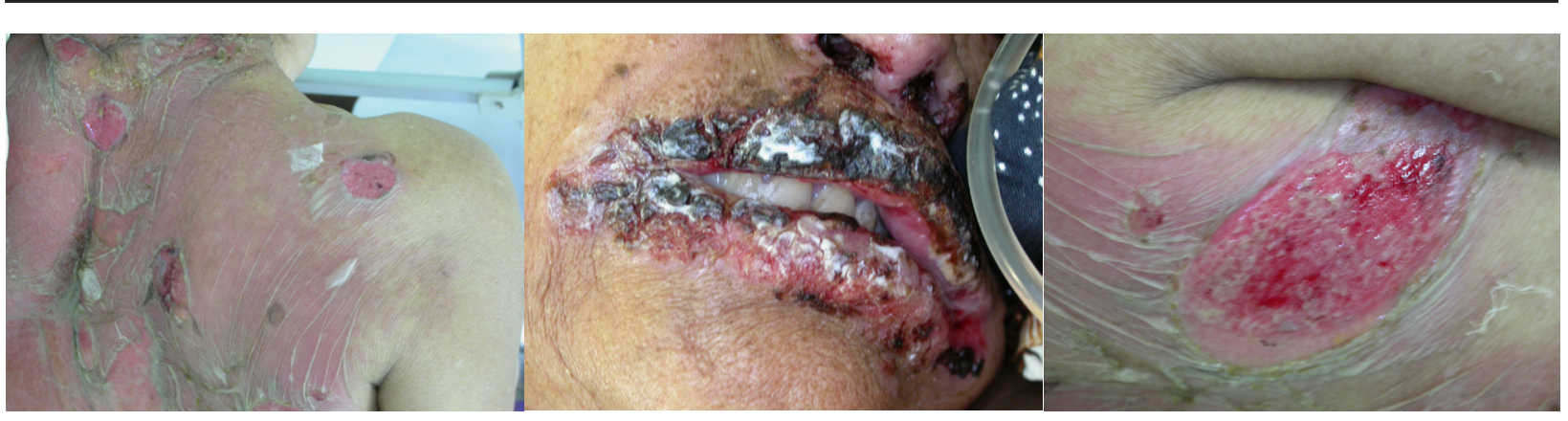

Figure 4. On day after one day medication in Dermatology and Venereal Deparment RSUPN-CM.

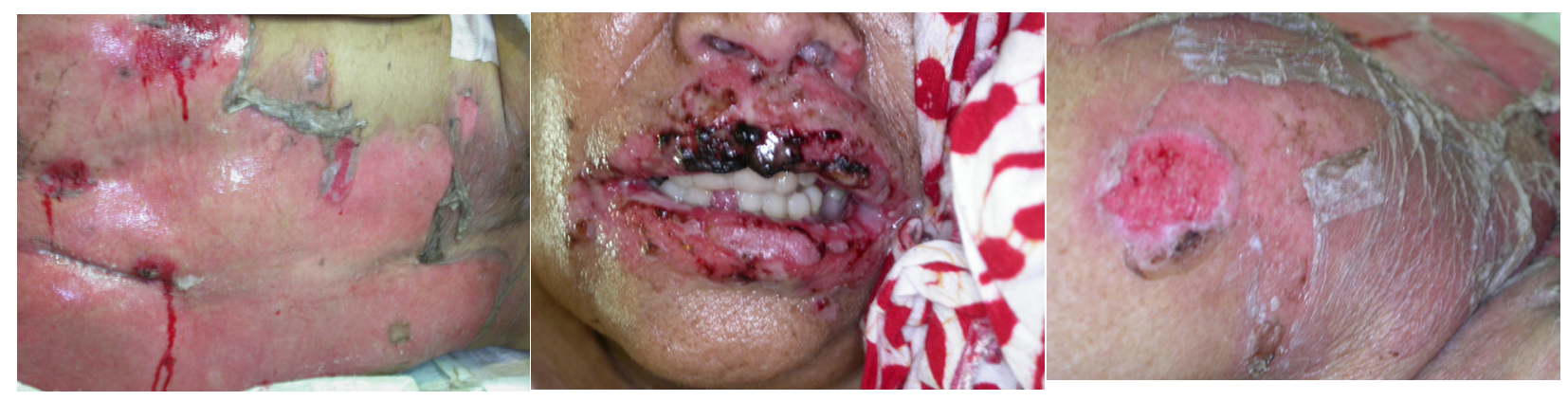

Figure 5. Patient condition two days after inhouse therapy.

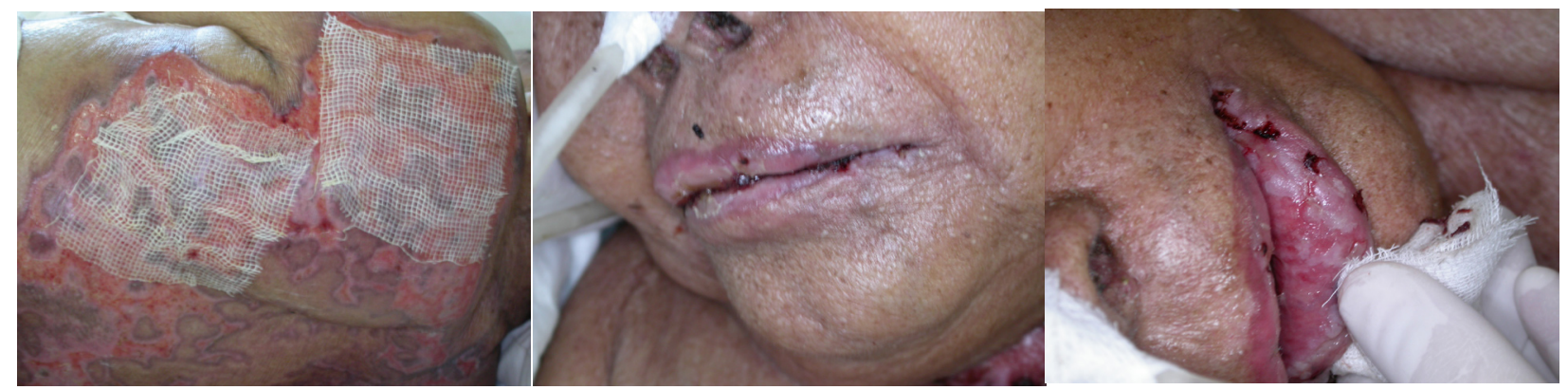

Figure 6. Patient condition after receive intravenous Methylprednisolon and Hidrocortisone lip topical cream.

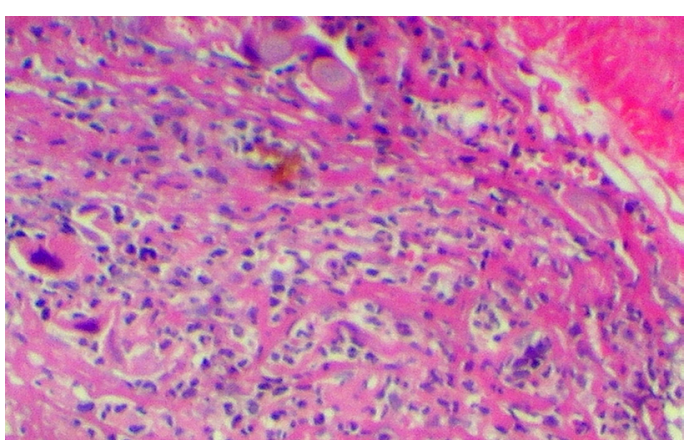

Figure 7. Histologic feature from lower labial mucous biopsy.

are bound to keratinocyte surface when the direct immunofluorescent feature of PV almost always shows intracellular autoantibody lgG, C3, and sometimes IgA is found. ${ }^{1,2,8}$ This mismatch is also seen on the histological appearance of the biopsy of the lower lip mucous that shows a lot of eosinophilic cells and inflammatory cells infiltration with no suprabasal vesicle and acantholitic cells. This shows an allergic condition (hypersensitivity) and inflammation that supports TEN more.

The later skin lesions are target lesions on foot, back and neck skin and unbroken vesicle at the back area, crust on the upper and lower lips and under the left eye. On oral mucous, sloughing and comprehensive erosive area and hypersalivation, pain while swallowing and difficulty in speaking were found. According to the patient's family, there was a chancroid-like wound on the genital area. This feature is the unique characteristics of Erythema Multiforme that develops later into Stevens Johnson Syndrome (SJS). ${ }^{3,8}$ Target lesion or iris lesion is vesicle in the central or a pale 
area surrounded by oedema and erithematous is a unique feature of Erythema Multiforme. ${ }^{1,4}$ SJS is said as a mnore severe type of erythema multiforme, epidermal sloughing affected less than $10 \%$ of body surface. ${ }^{1,3,9,10}$ In this patient, it was suspected that it would develop into TEN because the body surface that was affected was more than $10 \%$. However, the dermatology and veneral disease still confirmed that the appropriate diagnosis was pemphigus vulgaris. ${ }^{11}$

One day after the admission, sloughing on the back skin of the patient was seen but the integrity was still good, only loosen from the lower layer (as seen in Fig. 4) which is different from PV feature that show epidermal sloughing with thin roof and easily ruptured and broken that the integrity is loss. The answer from the referral to the opthalmologist show that there was dry eye et causa SJS that re-confirmed the diagnosis of SJS that developed into TEN.

The results of the patient's IgE examination showed a value that was 6 times higher than normal showing that patient experienced hypersensitivity. TEN is a hypersensitivity condition that is frequently triggered by medicine. The medicine that often triggers TEN reaction are sulphonamid, quinolone, anticonvulsant such as phenobarbitone, phenytion and carmabazepine. Erythromicine is suspected to trigger TEN although rarely. One of the theories estimated that the accumulation of the medicine metabolites in epidermis of individuals who has genetic predisposing factor may induce an immunologic process analogous with what happens in graft versus host disease. CD8 $8^{+}$lypmphocyte $T$ and macrophage activate inflammatory cascade leading to wide epidermal cell apoptosis. ${ }^{3}$

Patient suffered from depression since 20 years ago when her husband died and she was treated by a psychiatrist. For 20 years the patient has consumed various antidepressant and anticonvulsant but she did not remember all of them. The medicine most frequently used is valium. Valium is a type of benzodiazepine and has been reported as causing TEN in big dose. ${ }^{12}$ The mechanism of anticonvulsant that may cause hypersensitivity has not been fully understood. However, phenytoin, carbamazepine and phenobarbital have aromatic benzene ring. When the drug is metabolized by cytochrome enzyme system (CY) P-450 in the liver, the ring forms arene oxide metabolites that is difficult to remove. This will stimulate immune reaction that may cause cell damage. Arene oxide also strengthens covalent bound between cells and with the adjacent macromolecules that will directly become cytotoxic for the tissue and organ. ${ }^{13,14}$ This also strengthened the suspicion of drug hypersensitivity that is suspected to cause TEN.

Erythema Multiforme can be triggered not only by medicine but also by Herpes Simplex virus 1 and $2 .{ }^{1,2,9,10}$ In this patient, the result of the antibody test for HSV 1 and 2 was negative so that the suspicion of herpes virus as the causal agent can be eliminated.

TEN has the nature of rapid onset with high severity rate. ${ }^{1}$ The suspicion leads to various medicines received during treatment in several otherhospitalsbeforeshecametoRSUPN-CMleading to lesion on the skin. The medicines include aloe propolis cream, esilgan (triazolonbenzodiaxepine), Paracetamol, Mefenamic acid, Oxy-tetracycline $3 \%$, Forban cream (topical antibiotics $15 \mathrm{mg}$, Gentamicyn 0.1\%, Chloramphenicol, ketolorak, topical corticosteroid, and topical antifungus). Whether one of the medicines has triggered TEN could not be explained fully because we did not do allergy test for those medicines. This may become an important point to strengthen the diagnosis because several drugs are suspected to trigger TEN.

The patient's histological features do not show specific condition for TEN and SJS. However, sometimes the histological feature from TEN and SJS does not always specific. ${ }^{1}$ Basically, TEN and SJS give similar histological feature with keratinocyte apoptosis in epidermis with dermoepidermal separation that creates vesicle. TEN and SJS are induced by the reaction between Fas and Fas Ligand (FasL). Both are expressed by keratinocyte. ${ }^{15}$

The treatment of choice given for this patient was corticosteroid. Prednison is one of corticosteroid of choice for lesion in oral mucous with a dose of $1-2 \mathrm{mg} / \mathrm{kg}$ of weight. ${ }^{1,8}$ We gave Prednison $60 \mathrm{mg} /$ day for two months before the appearance of skin lesions and the response was quite well. When wide epidermolysis of the skin appeared, which was estimated as more than 10\% of the total body surface, the patient was admitted 
to the hospital and intravenous Methylprednisolon therapy was given. Methylprednisolon can block IgG that induces acantholysis leading to reduction of keratinocyte loosen expansion in epidermis. Therapy using methylprednisolon in pemphigus vulgaris may increase synthesis and modification of the end translation in keratinocyte attachment molecules. Systemic corticosteroid can reduce acantholysis on oral mucouse and skin in acute phase. ${ }^{16}$ However, the corticosteroid therapy is still not a specific therapy and it has disadvantageous side effects. In this patient, increased blood pressure and blood glucose is seen. Oral candidiasis was also found during corticosteroid provision. The therapy of choice in TEN is also corticosteroid but it is still controversial. The intravenous immunoglobulin (IVIG) provision in several case study is shown as giving very good result. ${ }^{17}$ IVIG contains anti Fas antibody that has the ability to block Fas that causes in vitro keratinocyte apoptosis. ${ }^{18}$

The dilemma in determining a fixed diagnosis for this patient between Pemphigus Vulgaris and TEN is still not solved due to limited availability of specific tests that can support the diagnosis of the two diseases. The determination of diagnosis is based more on the clinical appearance. It is possible that both diseases attack this patient and make each other worse which, off course, will lead to the need for further examination. The accurate diagnosis making is very important because it will determine the correct therapy. The good side of this case is that both Pemphigus Yulgaris and TEN needs corticosteroid therapy so that the difference in diagnosis will not be a problem.

\section{CONCLUSION}

Phempigus Vulgaris and Toxic Epidermal Necrolysis can present similar clinical appearance, i.e. oralmucouslesionandwidevesicleepidermolysis so that it is expected that the histological examination and direct immunofluorescent test can help to differentiate the two diseases. However, in this case the supporting examination results do not show specific feature that may be due to the inappropriate biopsy sampling area or inappropriate histological interpretation. Other tests that are more specific such as anti desmoglein 1 and 3 is needed to confirm PV or a serum test for
Fas and FasL is needed to confirm TEN. However, those specific tests are not available yet so that it leaves a dilemma in confirming the diagnosis for the disease.

\section{REFERENCES}

1. Greenberg M, Glick M. Burket's oral medicine. diagnosis \& treatment. $10^{\text {th }}$ ed. New Jersey: BC Decker Inc.; 2003. p. 57-70.

2. Field A, Longman L. Tyldesley's oral medicine. $5^{\text {th }}$ ed. London: Oxford University Press; 2002. p 130-6.

3. Falodun 0 , Ogunbiyi A. Dermatological emergencies. Current trends in management. Annals of Ibadan Postgraduate Med 2006;4:1521.

4. Dunant AA, Mockenhaupt M, Naldi L, Correia O, Schroder W, Roujeau JC, et al. Correlations between clinical patterns and causes of Erythema Multiforme Majus, Stevens-Johnson syndrome, and toxic epidermal necrolysis. Arch Dermatol 2002;138:1019-24.

5. Scully C, Challacombe SJ. Pemphigus Vulgaris. Update on etiopathogenesis, oral manifestations, and management. Crit Rev Oral Biol Med 2002;13(5):397-408.

6. Nguyen VT, Assane N, Grando SA. Novel human a9 Acetylcholine receptor regulating keratinocyte adhesion is targeted by Pemphigus Vulgaris autoimmunity. Am J Pathol 2000;157(4):1377-91.

7. Quin A, Brown K, Bonish BK, Curry J, Gordon KB, Sinacore J, et al. Uncovering histologic criteria with prognostic significance in toxic epidermal necrolysis. Arch Dermatol 2005;141:683-7.

8. Regezi JA, Sciubba JJ, Jordan RC. Oral pathology: Clinical correlations. $5^{\text {th }}$ ed. China: Elsevier; 2008. p. 10-4.

9. Lamoreux MR, Marna R, Sternbach, Teresa W. Erythema Multiforme. Am Fam Physician 2006 ;174(4).

10. GandolfoS, Scully C, Carrozzo M. Oral medicine. Philadelpia: Elsevier; 2006. p. 26-8.

11. Marks R. Roxburgh's common skin diseases. $17^{\text {th }}$ ed. New York: Oxford University Press Inc.; 2003. p. 91-2.

12. Huang P, Tsai W. Chlordiazepoxide-induced Stevens-Johnson syndrome. J Chin Med Assoc 2005;68:276-8. 
13. Marcus E, Mason. Anticonvulsant hypersensitivity syndrome: recognizing the signs and symptoms. Resident \& Staff Physician J 2007;53(3).

14. Krauss G. Current understanding of delayed anticonvulsant hypersensitivity reactions. Epilepsy Curr 2006;6:33-7.

15. Abe R, Shimizu T, Shibaki A, Nakamura H, Watanabe $\mathrm{H}$, Shimizu H. Toxic Epidermal Necrolysis and Stevens-Johnson Syndrome are induced by soluble fas ligand. Am J Pathol 2003;162(5):1515-20.

16. Nguyen V, Arredondo J, Alexander I.
Chernyavsky, Kitajima Y, Pittelkow M, et al. Pemphigus Vulgaris IgG and Methylprednisolone exhibit reciprocal effects on keratinocytes. J Biol Chemistry 2004;279(3):2135-46.

17. Magina S, Lisboa C, Goncalves E, Conceicao F, Leal V, Mesquita J. A case of toxic epidermal necrolysis treated with intravenous immunoglobin. Br J Dermatol 2000;142:191-2. 18. Prins C, Kerdel FA, Steven P, Hunziker T, Chimenti S, Viard I, et al. Treatment of toxic epidermal necrolysis with high-dose intravenous immunoglobulins multicenter retrospective analysis of 48 consecutive cases. Arch Dermatol 2003;139:26-32. 